University of Wollongong

Research Online

Faculty of Science, Medicine and Health -

Papers: Part B

Faculty of Science, Medicine and Health

$1-1-2020$

\title{
Why don't bushfire warnings work as intended? Responses to official warnings during bushfires in New South Wales, Australia
}

Joshua Whittaker

University of Wollongong, wjoshua@uow.edu.au

Melanie R. Taylor

Christopher Bearman

Follow this and additional works at: https://ro.uow.edu.au/smhpapers1

\section{Publication Details Citation}

Whittaker, J., Taylor, M. R., \& Bearman, C. (2020). Why don't bushfire warnings work as intended? Responses to official warnings during bushfires in New South Wales, Australia. Faculty of Science, Medicine and Health - Papers: Part B. Retrieved from https://ro.uow.edu.au/smhpapers1/1133 


\title{
Why don't bushfire warnings work as intended? Responses to official warnings during bushfires in New South Wales, Australia
}

\begin{abstract}
Australian fire services provide two broad types of warning to people in bushfire (or wildfire) risk areas. Fire Danger Ratings communicate the possible consequences of a bushfire due to its rate of spread, intensity and difficulty of suppression. Warnings are also issued to alert people to impending bushfires and advise them how to respond. This paper examines how people threatened and affected by bushfires in New South Wales, Australia, in 2017 understood, interpreted and acted upon warning messages they received. The research involved 113 semi-structured interviews and an online survey of 549 households. Results indicate that while most people found warnings easy to understand and useful, many did not respond in ways intended by fire services. Many waited until they were threatened before they evacuated, while others stayed to defend houses and property, assist or rescue other people, and protect pets and animals. Notably, the research highlights the tendency for people to seek confirmation of the bushfire threat before taking protective action, most commonly to avoid unnecessary evacuation and its associated costs. Furthermore, the research identifies three key messages in bushfire warnings that are not personally meaningful for many people because they do not align with how they are likely to respond to a bushfire. These include: (1) people should leave bushfire risk areas on days of Catastrophic fire danger, before there is a fire; (2) houses are not defendable under Catastrophic conditions; and (3) people should 'leave early'. The paper offers suggestions on how fire authorities can provide better information to help people to make more effective decisions by acknowledging and working within the context in which warnings are understood, interpreted and acted upon.

\section{Publication Details}

Whittaker, J., Taylor, M. \& Bearman, C. (2020). Why don't bushfire warnings work as intended? Responses to official warnings during bushfires in New South Wales, Australia. International Journal of Disaster Risk Reduction, 45
\end{abstract}


Why don't bushfire warnings work as intended? Responses to official warnings during bushfires in New South Wales, Australia

Joshua Whittaker ${ }^{1,4}$, Mel Taylor ${ }^{2,4}$, Chris Bearman ${ }^{3,4}$

1: Centre for Environmental Risk Management of Bushfires, School of Earth, Atmospheric and Life Sciences, University of Wollongong, Australia.

2: Centre for Elite Performance, Expertise and Training, Department of Psychology, Macquarie University, Australia.

3: Appleton Institute, Central Queensland University, Australia

4: Bushfire and Natural Hazards Cooperative Research Centre, East Melbourne

Phone: +61242981164

Email: wjoshua@uow.edu.au 


\section{Abstract:}

Australian fire services provide two broad types of warning to people in bushfire (or wildfire) risk areas. Fire Danger Ratings communicate the possible consequences of a bushfire due to its rate of spread, intensity and difficulty of suppression. Warnings are also issued to alert people to impending bushfires and advise them how to respond. This paper examines how people threatened by bushfires in New South Wales, Australia, in 2017 understood, interpreted and acted upon warning messages. The research involved 113 semi-structured interviews and an online survey of 549 households. Results indicate that while most people found warnings easy to understand and useful, many did not respond in ways intended by fire services. Notably, the research highlights the tendency for people to seek confirmation of the bushfire threat before taking protective action, most commonly to avoid unnecessary evacuation and its associated costs. Furthermore, the research identifies three key messages in bushfire warnings that are not personally meaningful for many people because they do not align with how they are likely to respond to a bushfire. These include: (1) people should leave bushfire risk areas on days of Catastrophic fire danger, before there is a fire; (2) houses are not defendable under Catastrophic conditions; and (3) people should 'leave early'. The paper offers suggestions on how fire authorities can provide better information to help people to make more effective decisions by acknowledging and working within the context in which warnings are understood, interpreted and acted upon.

Keywords: bushfire; wildfire; information; warnings; preparation; evacuation; defence. 


\section{Introduction}

Australian fire services issue warnings to alert people to the threat posed by bushfires (or wildfires) and to advise them how to respond. An important part of the warnings context in Australia is that people are permitted to choose whether they will leave (evacuate) when threatened by bushfire (preferably 'early') or stay to defend their houses and property against the fire (AFAC 2012; Handmer and Tibbits 2005; Whittaker et al. 2013). This is in contrast to other wildfire prone countries where evacuation is the norm (see Paveglio et al. 2012, McCaffrey et al. 2015, and McGee 2019 for discussion of the relative merits of the different approaches to wildfire response). Australian bushfire warnings, then, may encourage people to leave, initiate property defence or, if evacuation is deemed unsafe, to seek shelter. Fire services invest considerable amounts of time and money trying to get the wording and timing of warning messages right. Yet there is a growing literature that suggests people do not always respond to warnings in ways fire services intend. Research has shown that some people in bushfire risk areas are unaware of the risk (e.g. Whittaker et al. 2013; Horsey and Penman 2014), are not adequately prepared to safely respond (e.g. Eriksen and Gill 2010; Penman et al. 2013) and wait until the last moment before evacuating (e.g. Haynes et al. 2010; McLennan et al. 2015). Some even enter fire affected areas to return to their properties, and may evade road blocks to do so (Wilkinson et al. 2016).

This paper contributes to this literature by examining how people threatened and affected by bushfires in New South Wales (NSW), Australia, in 2017 understood, interpreted and acted upon warning messages they received. This provides a case study of the ways that people behave when they receive a warning message, in contrast to the way that the fire and emergency services intend for people to respond when they send out the messages. This study then seeks to determine the extent to which warning messages sent by a particular fire agency were useful and meaningful for the people who received them. The research is focused on responses to warnings sent during bushfires in New South Wales (NSW) in 2017 and within the somewhat unique approach to bushfire safety used in Australia. Nevertheless, findings about why people do not respond to warnings in ways intended by fire and emergency services may provide insights into delayed warning response or non-response for wildfires in other countries (e.g. Cohn et al. 2006; McCaffrey et al. 2018) or for other hazards.

\section{Australian bushfire warning systems}


In Australia, responsibility for issuing bushfire warnings rests with state and territory fire services (Anderson-Berry et al. 2018). Two main types of warnings are issued: information about predicted danger if a fire were to start (in the form of Fire Danger Ratings); and alerts about impending fires that may impact on people or a community.

The Fire Danger Rating (FDR) is a warning system that produces and communicates information about possible consequences of a bushfire based on predicted conditions including temperature, humidity, wind and landscape dryness (CSIRO 2018). Regionallyspecific FDRs are issued daily, for the following day, regardless of whether there is a fire, via multiple channels including weather forecasts, websites and social media, radio and television broadcasts, and newspapers. Prior to 2009 there were five FDRs: Low; Moderate; High; Very High; and Extreme. After the 2009 Black Saturday bushfires, which killed 173 people and destroyed over 2000 homes in the state of Victoria, 'Severe' and 'Catastrophic' FDRs were introduced. These ratings were intended to communicate the increased risks to life and property on the days of highest fire danger, when conditions demand a different response (Teague et al. 2010). Table 1 outlines current FDRs and advice from the NSW Rural Fire Service (NSWRFS) for each level of fire danger. This general advice is intended to help people consider their options and plan their response to bushfire. Actual warnings about fire danger are more concise and directive. For example, a warning sent via SMS to people in the Hunter, Central Ranges and North Western regions of NSW in 2017 read as follows:

'Dangerous fire weather across NSW. Catastrophic fire danger forecast in some areas. Avoid bush fire prone areas. Info: www.rfs.nsw.gov.au or 1800679737’.

\begin{tabular}{|l|l|}
\hline Fire Danger Rating & What you should do \\
\hline Catastrophic & $\begin{array}{l}\text { For your survival, leaving early is the only option. } \\
\text { Leave bush fire prone areas the night before or early in the day - do } \\
\text { not just wait and see what happens. } \\
\text { Make a decision about when you will leave, where you will go, } \\
\text { how you will get there and when you will return. } \\
\text { Homes are not designed to withstand fires in catastrophic } \\
\text { conditions so you should leave early. }\end{array}$ \\
\hline Extreme & $\begin{array}{l}\text { Leaving early is the safest option for your survival. } \\
\text { If you are not prepared to the highest level, leave early in the day. } \\
\text { Only consider staying if you are prepared to the highest level - such } \\
\text { as your home is specially designed, constructed or modified, and } \\
\text { situated to withstand a fire, you are well prepared and can actively } \\
\text { defend it if a fire starts. }\end{array}$ \\
\hline Leaving early is the safest option for your survival. \\
\hline Severe &
\end{tabular}




\begin{tabular}{|l|l|}
\hline & $\begin{array}{l}\text { Well prepared homes that are actively defended can provide safety } \\
\text { - but only stay if you are physically and mentally prepared to } \\
\text { defend in these conditions. } \\
\text { If you're not prepared, leave early in the day. }\end{array}$ \\
\hline Very high & $\begin{array}{l}\text { Review your bush fire survival plan with your family. Keep } \\
\text { yourself informed and monitor conditions be ready to act if } \\
\text { necessary. }\end{array}$ \\
\cline { 1 - 2 } Low-moderate &
\end{tabular}

Table 1: Fire Danger Ratings and associated advice (NSWRFS 2018)

Fire services also issue warnings to alert people to impending bushfires and provide advice on how to respond. All state and territory warning systems use a three-level alert process:

1) 'Advice' indicates that a fire has started but there is no immediate danger. People are advised to stay up to date in case the situation changes.

2) 'Watch and Act' - indicates a heightened level of threat. People are advised that conditions are changing and they need to start taking action to protect themselves and their family.

3) 'Emergency Warning' indicates people are in danger and immediate protective action is required.

This process was developed as part of the National Framework for Scaled Advice and Warnings to the Community. The process of escalation of alerts from Advice through to Emergency Warning is intended to minimise 'over-warning' or warning fatigue (AEMC 2009). The exact wording and advice contained in warnings depends on the warning channel (e.g. landline telephone; SMS; radio broadcast etc.) and the action that is advised (e.g. evacuate; shelter-in-place). Fire services use a range of channels to communicate warnings including mobile and landline telephones, mobile phone apps, radio, television and social media.

\section{Public responses to warnings}

\subsection{Effective warnings}

Generally, a good warning message is distinguished from a poor one by its content including information about the nature, location, guidance, time, and source of the hazard or risk - and style - including its specificity, consistency, accuracy, certainty, and clarity 
(Sorensen 2000). Wood et al. (2018) reviewed warnings research for hazards and disasters, finding that effective warning messages: (a) describe the hazard or event, including the threat posed, the consequence of the hazard's impact, and how advised actions can reduce such consequences; (b) provide protective action guidance, explaining exactly how to take recommended actions; (c) specify the location of the event, stating who will and will not be affected and where people who will need to take protective action are located; (d) provide a time when people should begin taking protective action and when it should be completed; (e) state who the message is from, preferably a mixed panel of the most credible official and familiar sources; and (f) are clearly worded, specific about what is said, accurate and complete in the information provided, clear and unambiguous, and consistent.

\subsection{Responses to warnings}

Researchers have tended to characterise warning response as a primarily cognitive, linear process involving a number of stages. For example, Lindell and Perry (1992) understand warning response as a sequential, four-stage process in which a message receiver asks a series of questions that shape their response. The first stage involves risk identification, where the receiver asks: 'Does the threat exist?' Second, the receiver makes a risk assessment, asking: 'Is protection needed?' Third, an assessment of risk reduction options is made, with the receiver asking: 'Is protection feasible?' And finally, the receiver considers possible protective responses, asking: 'What action to take?' In a similar vein, Mileti and Sorensen (1990) describe a six-stage process involving: 1) hearing the warning; 2) understanding the contents of the warning message; 3 ) believing the warning is credible and accurate; 4) personalising the warning to oneself; 5) confirming the warning is true and that others are taking heed; and 6) responding by taking protective action. Factors influencing warning response include characteristics of the message sender, the receiver, the message itself, and the social context in which the message is received (Mileti and Sorensen 1990; Mileti 1999).

There are many reasons people may not respond to warnings in a timely manner. Drabek (1999, p. 15) suggests that '... the first principle in understanding disaster warning responses is to recognize explicitly that the initial response to any warning is 'denial'. However, a recent review of 'denial' in hazards and disaster research found little critical discussion of the concept (McLennan et al. 2017). Furthermore, most of the studies used denial to explain failures to perceive and mitigate risk in advance of a hazard, rather than to explain warning 
response delay or non-response. Nevertheless, research confirms that certain cognitive biases may influence warning responses (Omori et al. 2017). In particular, normalcy bias may cause people to underestimate the possibility of a hazard occurring and its possible effects, which may reduce receptiveness to warnings. When people recognise that a hazard may occur, optimism bias can prevent them from personalising risk and therefore responding to warnings (Omori et al. 2017). Prior experience with hazards and warnings may also influence responses. Some studies have found that prior hazard experience increases the likelihood of warning response, specifically evacuation (Sharma and Patt 2012), while repeated exposure to 'false alarms' may impede or prevent responses to future warnings (e.g. Dow and Cutter 1998; Mackie 2014).

Social context is also important in understanding warning responses. When someone receives a warning, they consider its meaning in relation to the ongoing stream of events in which they are engaged (Brenitz 1983). This seems to be the case even when the warning is received in the context of a situation that requires immediate compliance (such as an aircraft ground proximity warning; DeCelles 1991). Historically, natural hazards research has understood decision-making as a primarily cognitive process engaged in by individuals, rather than a complex social process involving groups of people with different experiences, perspectives and interests (Walker 1979). This perspective is evident in the 'stimulus-response' models of hazard response discussed above (Mileti and Sorenson 1990; Lindell and Perry 1992) in which individuals receive information about a hazard, consider their options and then choose how they will respond (Basset and Fogelman 2013). However, as Drabek (1999) has noted, much of the complexity in warning response is due to the fact that people are usually with someone else when they receive a warning. Thus it is often groups, rather than individuals, that 'process' warnings. This group processing of warnings rarely leads to an immediate consensus as to what should be done (Drabek 1999). For example, research into the 2009 Black Saturday bushfires in south-eastern Australia highlighted the discussion and debate that occurred in many households about whether it was necessary to evacuate (Whittaker et al. 2016). Similarly, a study of people evacuated from the north coast of New Zealand during the 2009 Samoan Tsunami found people discussed the warning they received with friends and peers before taking protective action (Couling 2014).

The tendency for people to seek confirmation of warning messages before taking protective action is well documented (e.g. Perry 1979; Mileti and Sorenson 1990; Parker and Handmer 
1998; Bean et al. 2015; Wood et al. 2018). After receiving a warning people will almost always attempt to confirm the warning message by surveying the environment, observing the behaviour of others, talking to friends or relatives, or contacting some official source. When people are unable to confirm the message - for example because there is no sign of the hazard in the environment, or others appear unconcerned - they are less likely to take protective action in a timely manner (Perry 1979). Wood et al. (2018, p. 556) propose that the process of confirming warning messages can be characterised as 'milling', whereby people interact with others (mill) in order '... to generate new perceptions and norms to guide their behavior in unfamiliar circumstances'. Their experimental study examining participants' envisaged responses to a hypothetical warning about an explosion of an improvised nuclear device suggests that longer warning messages may reduce people's inclination to confirm and search for more information, thereby shortening response delay. However, Parker and Handmer (1998) note that, while warning systems may attempt to provide confirmation, those who are at risk usually seek out alternative information sources. Thus, to at least some extent, and whether it is beneficial or detrimental to warning response, confirmation remains a certain feature of the warning process (Brotzge and Donner 2013).

\subsection{Responses to bushfire warnings}

In Australia, research suggests people typically find official warning messages easy to understand and useful (Horsey and Penman 2014; Trigg et al. 2014; Every et al. 2016). For example, Horsey and Penman (2014) found most respondents impacted by the October 2013 NSW bushfires agreed the warnings they received were 'clear' (73\%), 'relevant' (71\%) and 'sufficient' (69\%). Respondents judged information obtained via radio to be 'useful' (90\%), 'timely' (85\%), of the 'right frequency' (87\%) and 'sufficiently localised' (78\%). Similarly, information obtained via the internet was seen as 'useful' (94\%), 'up to date' (76\%) and 'sufficiently localised' (83\%).

A number of studies have found that most people find out about bushfires not from official warnings but via environmental cues and communication with family, friends and neighbours (Strahan, 2018; Whittaker et al. 2013). Half of all survey respondents $(n=1314)$ affected by the 2009 Black Saturday fires found out about the fire by seeing or smelling smoke (32\%) or through communications with family, friends or neighbours (21\%). Less than one-tenth found out via an official warning (8\%) (Whittaker et al. 2013). Similarly, Strahan (2018) found that residents affected by the 2014 Perth Hills and 2015 Adelaide Hills fires commonly became 
aware of the fire via environmental cues (55\%) and communications with family, friends and neighbours (21\%). One-fifth became aware of the fire after receiving an official warning $(8 \%)$ or obtaining emergency information via television, radio, social media or emergency service websites and apps (16\%). Numerous studies have outlined the importance of unofficial warnings to public responses in emergencies and disasters (e.g. Parker and Handmer 1998; Nagarajan et al. 2012; Cheshire 2015).

Other research has highlighted the tendency for people to wait until they are threatened before taking protective action (e.g. Rhodes 2005; Whittaker and Handmer 2010; McLennan et al. 2013 and 2015; Strahan et al. 2018). For example, Rhodes (2005) surveyed 718 households in bushfire risk areas of Victoria, finding approximately 60 percent intended to wait until a fire was threatening before deciding whether to evacuate or stay and defend. Similarly, McLennan et al.'s (2015) review of seven post-bushfire interview studies found 'appreciable' proportions (ranging from 5-29\%) intended to 'wait and see'. This approach is discouraged by Australian fire services because it increases the risk that people will evacuate at the last minute or become trapped in locations where safe sheltering or defence is not possible (Haynes et al. 2010; Blanchi et al. 2014; Whittaker et al. 2017).

Relatively few studies have examined intended and actual responses to FDRs and associated advice. Research following the introduction of the 'Code Red' FDR in Victoria (the equivalent of a Catastrophic FDR in other states) in 2009 found 50-60\% of residents intended to leave on Code Red days, with many intending to leave the night before or early in the morning (i.e. before a fire started or threatened) (Whittaker and Handmer 2010). However, a subsequent survey of 602 residents following a Code Red day found that two-thirds remained at their home or property (Strahan Research 2010). Of the third that was not at home, just $1.5 \%$ left because of the Code Red FDR. Asked how they would respond to a future Code Red FDR, almost three-quarters $(73 \%)$ indicated they would not leave the night before or early in the morning, as advised by the Country Fire Authority (CFA). Three-quarters (78\%) of those who intended to leave on a future Code Red day said they would only do so once there was a fire (Strahan Research 2010). A meta-analysis of seven post-bushfire interview studies between 2009 and 2014 (McLennan et al. 2015) found 'appreciable' percentages of householders (ranging from 27-52\%) stayed to defend their properties under Extreme and Catastrophic/Code Red fire danger conditions, despite advice emphasising leaving as the safest option. 
This paper, then, examines the responses of people to bushfire warnings sent during bushfires in NSW in 2017. It considers whether people found the warnings they received easy to understand and useful but more importantly investigates how people responded to these warnings. In particular, we were interested in any mismatch between actions recommended by the fire service and actions carried out by members of the community. The reasons why such mismatches occur can potentially provide important information about the kinds of factors that prevent people from responding to warnings in a timely manner. This potentially provides important information for fire services that can be used to enhance the way that public information and warnings are provided during natural hazards.

\section{Research methods}

The research involved semi-structured interviews with people threatened and impacted by three bushfires in NSW in 2017 and an online survey of people living in bushfire risk areas in NSW. The research focused on a range of issues related to people's planning, preparation and responses to bushfires (see Whittaker and Taylor 2018) and was funded by the NSWRFS. Ethics approval was obtained from the University of Wollongong Human Research Ethics Committee (Ethics no. 2017/216).

\subsection{Semi-Structured Interviews}

139 semi-structured interviews were conducted in June and July 2017 with 146 people affected by the Currandooley (36 interviews), Taliesen Road (38) and Sir Ivan (39) fires (see Table 2). The interviews comprised open-ended questions about: perceptions and understandings of bushfire risk; planning and preparation; intended and actual responses; and impacts of the fires on people, property, animals and other values (e.g. environmental amenity). Semi-structured interviewing allows interviewees to frame and structure their responses according to their own personal experiences and narratives. The advantage of this approach is that the interviewee's perspectives and experiences unfold as the participant views it, not as the interviewer views it (Marshall and Rossman 2014). This allows interviewees to tell their own, unique story and can help researchers to identify issues, perspectives and lines of questioning not previously considered.

\begin{tabular}{|l|l|l|l|l|}
\hline Fire & Date & FDR & Areas affected & Impacts \\
\hline Currandooley & 17 January 2017 & Severe & Tarago and Mt Fairy & - 3,378 hectares of \\
\hline
\end{tabular}




\begin{tabular}{|c|c|c|c|c|}
\hline & & & & $\begin{array}{l}\text { land burnt } \\
\text { - One house and } \\
\text { multiple sheds } \\
\text { destroyed } \\
\text { - Two vehicles } \\
\text { destroyed } \\
\text { - } 20 \text { sheep and } \\
\text { cattle killed and } \\
\text { losses of } \\
\text { agricultural assets } \\
\text { including fences } \\
\text { and pasture }\end{array}$ \\
\hline Sir Ivan & 12 February 2017 & Catastrophic & $\begin{array}{l}\text { Dunedoo, Leadville, } \\
\text { Cassilis, Coolah and } \\
\text { Uarbry }\end{array}$ & $\begin{array}{l}\text { - } 55,37 \text { hectares of } \\
\text { land burnt } \\
-35 \text { houses, } 131 \\
\text { outbuildings and } \\
\text { two community } \\
\text { buildings } \\
\text { destroyed } \\
\text { - Significant losses } \\
\text { of livestock and } \\
\text { agricultural assets } \\
\text { including fences } \\
\text { and pasture }\end{array}$ \\
\hline Taliesen Road & 17 February 2017 & Very High & Carwoola & $\begin{array}{l}-3,134 \text { hectares of } \\
\text { land burnt } \\
-11 \text { houses and } 45 \\
\text { outbuildings } \\
\text { destroyed } \\
\text { - Losses of } \\
\text { agricultural and } \\
\text { other assets } \\
\text { including fences, } \\
\text { pasture, gardens } \\
\text { and animals }\end{array}$ \\
\hline
\end{tabular}

Table 2: Outline of the fires studied

Interviews were undertaken in participants' homes and, in a few cases, at local fire brigade sheds or cafes. Some interviews were undertaken with more than one person. Participants were given time to read a participant information sheet prior to the interview commencing, and written consent was obtained. Interviews typically lasted for 45 minutes to one hour and were audio recorded with participants' consent. Audio recordings were transcribed in full, generating over 2100 pages of interview transcript. NVivo 11 (QSR International) was used to analyse the transcripts. Categories into which segments of text could be grouped (known as 'nodes' in NVivo) were developed in collaboration with NSWRFS. Data relating to bushfire warnings and information were sought by NSWRFS and collated using the following nodes: (a) effectiveness of Catastrophic fire danger warnings; (b) effectiveness of bushfire warnings; and (c) how people obtained bushfire-related information. The process of analysing 
interviews involved reading transcripts in full and selecting text to assign to relevant nodes ('coding'). This process enabled segments of text to be grouped into relevant nodes to enable closer analysis (Thomas 2006).

\subsection{Online Survey}

A questionnaire was developed in consultation with the NSWRFS to survey areas throughout NSW that were threatened by bushfires and/or experienced Catastrophic fire danger in 2017 (see Whittaker and Taylor 2018, Appendix 3). The purpose of the questionnaire was to gather quantitative data on issues and themes explored in the interviews. The questionnaire comprised 23 questions about warnings and information people received or obtained during the period of bushfire threat. For each warning source (see Table 4) respondents were asked to indicate whether they believed warnings were timely, up to date, easy to understand, sufficiently localised and useful. The online survey launched on the SurveyMonkey.com website on Thursday 17 August and closed on Sunday 24 September 2017. 624 responses were received. 75 responses were deemed insufficiently complete because no questions, or only demographic questions, were answered. These responses were removed, leaving a total of 549 responses with an $89 \%$ completion rate. Half of all survey respondents $(52 \%, n=253)$ indicated they were impacted or threatened by a bushfire in NSW in 2017. Key characteristics of the online survey are outlined in Table 3. Online survey data were analysed using the SPSS Statistics software.

- Gender: $61 \%$ women; $38 \%$ men; $1 \%$ identified as an 'other' gender.

- Age: 8\% 18-24; 17\% 25-34; 24\% 35-44; 25\% 45-54; 19\% 55-64; 6\% 65-74; $1 \%$ 75+

- Property type: $44 \%$ house or unit on residential block; $37 \%$ house on a hobby farm or small acreage; $16 \%$ house on a large farm property.

- Occupancy: $95 \%$ primary place of residence.

- Tenure type: $80 \%$ owned with or without mortgage; $16 \%$ renting; $2 \%$ managing house or property; $3 \%$ other arrangement.

- Tenure length: 39\% 0-5 years; 20\% 6-10 years; 21\% 11-20 years; $19 \%$ 20+ years.

- Household composition: $47 \%$ couple with children or dependents; $27 \%$ couple without children or dependents; $10 \%$ shared house with other adults; $6 \%$ single-pare households; $6 \%$ single-person households.

- Animals: $73 \%$ pets or companion animals; $21 \%$ horses; $18 \%$ 'pet' livestock; $15 \%$ commercial livestock; $14 \%$ working or service dogs.

- Association with NSWRFS: 29\% volunteer members; $8 \%$ past members; $10 \%$ Community Fire Unit members. 
Table 3: Key characteristics of the online survey sample

\subsection{Limitations}

The study has a number of limitations. The interview sample was opportunistic in the sense that researchers visited properties on weekdays during business hours and interviewed residents who were present at the time. As such, those who work during business hours or were living elsewhere because their home was destroyed are probably underrepresented in the sample. However, this limitation was anticipated in the study design and attempts to counter it were made via a letterbox drop and distribution of invitations to participate via local networks (Facebook, email lists etc.). A number of interviews were arranged out of business hours and at alternate locations with these residents. While the interviews were conducted relatively soon after the fires (within six months), it is possible that participants may have been unable to recall some details. The online survey was primarily advertised through the NSWRFS Facebook page and volunteer members were well represented in the sample. While the sample captures considerable diversity in demographic characteristics, property types and bushfire knowledge and preparedness (see Table 2), it cannot be claimed to be representative of the wider population. Additionally, hindsight bias - where outcome information influences respondents' recollections of their prior knowledge or beliefs (Bradfield and Wells 2005) may have influenced some of the data collected. Social desirability bias - where respondents give responses in a way they deem to be more socially acceptable than would be their 'true' response (Lavrakas 2008) - is unlikely to have influenced data given that the questionnaires were anonymous and many interviewees were openly critical of warnings and in many cases described responses that contravened the advice of authorities.

\section{Results}

\subsection{Fire Danger Ratings and associated warnings}

Just under half of all survey respondents $(46 \%, n=231)$ received an official warning via SMS or telephone about the Catastrophic FDR. This warning states that homes are not designed to withstand fires in catastrophic conditions so leaving early is the only safe option. The warning further states that people should leave bushfire prone areas the night before or early in the day and not just wait and see what happens (see Table 1). Most thought the warning was easy to understand $(88 \%, \mathrm{n}=197)$, timely $(83 \%, \mathrm{n}=192)$ and useful $(78 \%, \mathrm{n}=174)$. 
Respondents on residential blocks more often found the warning useful $(84 \%, n=76)$ than those on large farm properties $(70 \%, n=32)$ and hobby farms/small acreages $(74 \%, n=62)$.

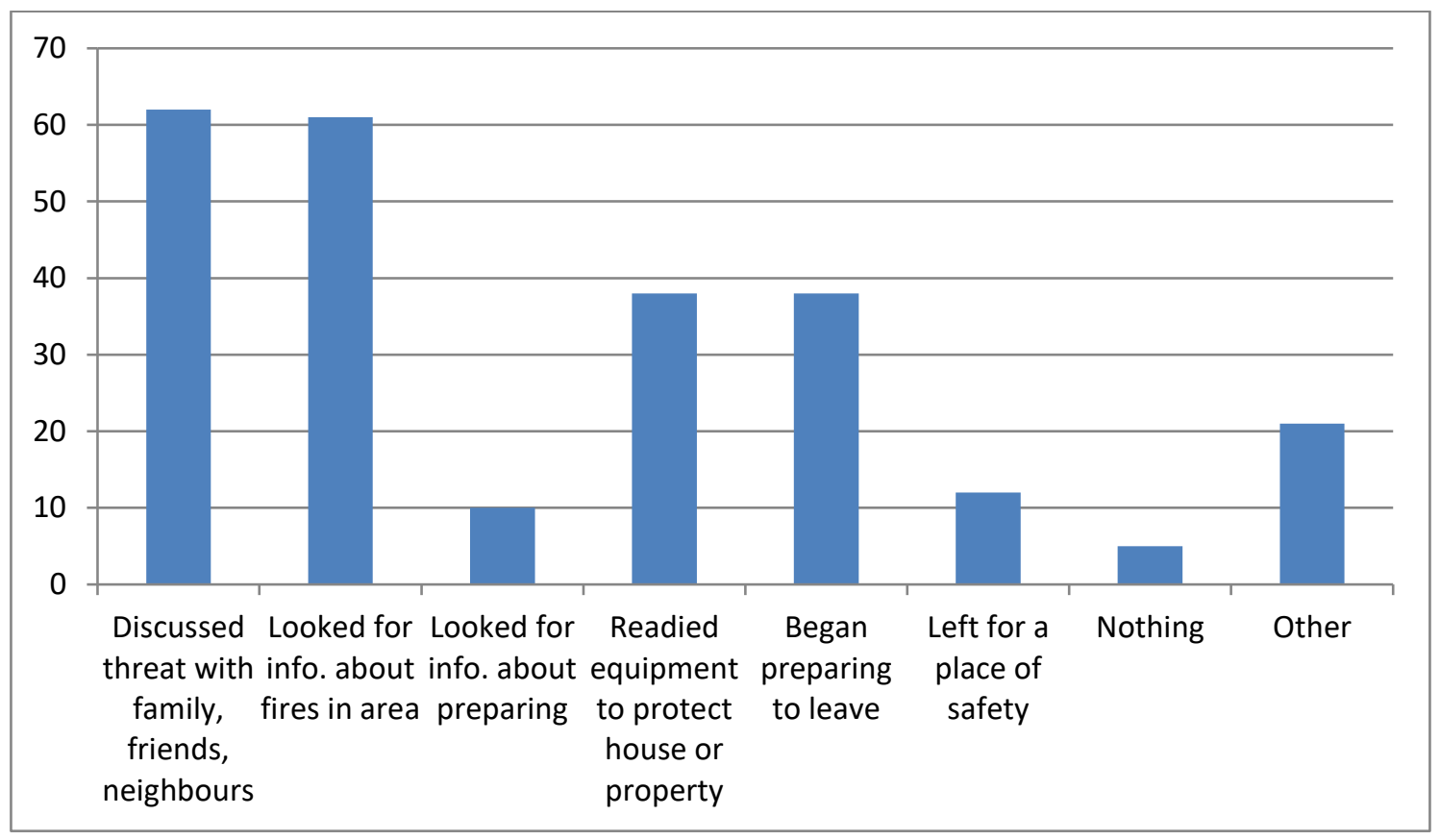

Figure 1: Response to Catastrophic FDR (\%, $\mathrm{n}=231)$

After receiving the warning, respondents most commonly discussed the bushfire threat with family, friends or neighbours $(62 \%, n=143)$ and looked for information about bushfires in their area $(61 \%, \mathrm{n}=141)$. More than a third of respondents got equipment ready to protect the house or property $(38 \%, \mathrm{n}=88)$ or began preparing to leave $(38 \%, \mathrm{n}=87)$. A much smaller proportion left for a place of relative safety after receiving a warning about the Catastrophic FDR $(12 \%, \mathrm{n}=28)$, as is advised by fire services.

When asked what they would do if a Catastrophic FDR was issued for their area next summer, $12 \%$ of respondents $(n=28)$ indicated they would leave before there was a fire and $24 \%$ said they would wait for a fire and then leave $(n=53)$. One-quarter intended to wait to see if there was a fire before making a decision about whether to stay or leave $(24 \%, n=53)$ and a similar proportion said they would get ready to protect their house and property $(27 \%$, $\mathrm{n}=60)$. A small proportion said a Catastrophic FDR would not influence what they did (4\%, $n=9)$. 
Of the three sites where interviews were undertaken, Sir Ivan was the only fire to burn under Catastrophic fire danger conditions. Most interviewees were aware of the Catastrophic rating. Graziers and other farmers appeared particularly cognisant of the risks if a fire was to start, and some began preparing to move their livestock in case of a fire. For example, an interviewee explained her family's decision to remain on the farm instead of attending the Dunedoo Show (similar to a carnival or fair):

It was 40 degrees [Celsius] at 8:00 in the morning. We've got little kids, so we decided we weren't going to go [to the Show]. My husband wasn't really comfortable leaving the farm on such a bad day... so we ended up staying here... On the Saturday afternoon we started mustering [approx. 600 head of cattle] because, as you can see, we've got Lucerne around the house here, and we actually had 60 hectares of sorghum crop, which is a very green summer crop... Our plan was that all the stock would go onto that, because it would be a pretty good buffer.... We've got a fire truck and a grader and a backhoe... We just got everything sorted, so that we were ready for anything. - Cassilis, Sir Ivan Fire

Others appeared to be aware of the Catastrophic FDR but acknowledged the warning had not really influenced their planning or preparation for bushfire.

Interviewee: We did hear on the news about Sunday being a Catastrophic risk day, which was well predicted... In hindsight, no, we weren't ready at all. Didn't have a plan that would've worked...

Interviewer: So the Catastrophic warning didn't influence anything you did? Interviewee: Only to monitor it. No, not really. - Coolah, Sir Ivan Fire

Even when the Sir Ivan Fire had started, and despite awareness of the Catastrophic conditions, some residents could not comprehend that a fire could reach them. The interview excerpts below suggest while people may understand that 'Catastrophic' denotes the worst possible conditions for bushfires, they may not understand what this means for fire behaviour. In particular, it appears some people did not appreciate the speed and distance that a fire burning under Catastrophic fire danger conditions could travel: 
Those warnings, they did get through... Yeah, we were all aware of that. Even with knowing that it was Catastrophic, we still didn't, couldn't... It wasn't within our minds to picture that a fire could travel that far. - Coolah, Sir Ivan Fire

I didn't think it was close and I didn't have any idea it was moving as fast as it was. I've seen bushfires with a front where it eats its way along, but this thing! When the [road] verge exploded into flames, the actual fire front was probably half a kilometre away.Uarbry, Sir Ivan Fire

Interviews with people affected by the Currandooley and Taliesen Road fires also provided insights into how people understand and intend to respond to Catastrophic FDRs. Some had firm plans to leave on Catastrophic fire danger days, but stressed they would only leave once a fire started. Leaving in the absence of a fire was widely regarded as unnecessary or impractical:

Male: I know through being in the fire brigade that if it's Catastrophic you should leavewhether there is a fire or not. I don't know if I agree with that, and I don't think you could convince a lot of people in the community to do that.

Female: I mean, if it was just a normal day, you'd go to work, the kids would go to school...

Interviewer: But what if it was school holidays? Over summer? You wouldn't be leaving if there was a Catastrophic Fire Danger Rating without a fire?

Male: I don't think so. If there was a fire, that's different.

Female: I don't think we would. I mean, I think you'd certainly be conscious of it. You would have it in the back of your mind, but I don't think we would go. - Carwoola, Taliesen Road Fire

Interviewer: Would you leave on Catastrophic days, even if there's no fire?

Male: Not going to happen. I think that's really unrealistic, especially for people that have livestock... The logistics of that are just ridiculous... If it was just people in a house and it was a case of 'Oh, we'll go and stay at grandma's or we'll go and do whatever,' that would be fine. But in a rural area like this, I think that's really difficult to do. - Carwoola, Taliesen Road Fire 
Others had considered the risks on days of Catastrophic fire danger but said they would not leave their house and would enact their plan to stay and defend. For example:

We'd still stay and we'd carry out our plan [to defend] anyway. I'm confident we would do that. But I think we would be a lot more nervous. We would be looking for things to go wrong. But then, as I say, we're getting older and sooner or later we're probably gonna get to a stage where we can't do this stuff anymore, in which case we might have to go away. But that's gonna be a while down the track I think. - Mount Fairy, Taliesen Road Fire

\subsection{Bushfire warnings and information}

Survey results suggest a high degree of public satisfaction with bushfire warnings. As shown in Table 4, most respondents (approx. 80\%) believed warnings were easy to understand and useful. The majority thought warnings were timely, up-to-date and sufficiently localised; however, there was a considerable proportion that did not. For example, $39 \%$ of respondents did not think official warnings via landline telephone were sufficiently localised. Around one-third did not think SMS warnings were timely, up to date or sufficiently localised.

\begin{tabular}{|c|l|c|c|c|c|}
\hline & Timely & Up to date & $\begin{array}{l}\text { Easy to } \\
\text { Understand }\end{array}$ & $\begin{array}{l}\text { Sufficiently } \\
\text { localised }\end{array}$ & Useful \\
\hline Landline telephone & $68(n=34)$ & $72(n=36)$ & $78(n=39)$ & $53(n=26)$ & $78(n=40)$ \\
\hline SMS & $66(n=78)$ & $66(n=78)$ & $86(n=105)$ & $64(n=76)$ & $67(n=78)$ \\
\hline Radio & $76(n=56)$ & $64(n=47)$ & $87(n=65)$ & $73(n=54)$ & $82(n=61)$ \\
\hline Fires Near Me & NA & $66(n=130)$ & $88(n=172)$ & $76(n=148)$ & $82(n=159)$ \\
\hline $\begin{array}{c}\text { RFS updates, } \\
\text { interviews, media } \\
\text { conferences }\end{array}$ & $71(n=111)$ & $68(n=108)$ & $84(132)$ & $69(n=109)$ & $73(n=114)$ \\
\hline
\end{tabular}

Table 4: Survey respondents' assessments of official warnings (in percentages)

It is important to recognise that survey respondents were threatened to varying degrees by different fires, which will have influenced the timing, content and relevance of warnings to receivers. Nevertheless, the results presented in Table 3 suggest, overall, a high degree of satisfaction with the warnings and information received.

Many interviewees were already aware of the fire when they received an official warning via telephone or SMS. They often became aware of a fire by seeing or smelling smoke, through 
communication with relatives, friends and neighbours, or by seeing or hearing activity associated with firefighting, such as sirens. However, for some, receipt of a warning communicated the danger posed by the fire and confirmed the need to take action:

Female: It was reinforcing that the fire was a problem. Some people said they didn't get any notification, but he had a phone, I had a phone, and we both got the message.

Male: We were certainly notified. It was nice to hear it. Just to know that we were not doing things for nothing, I suppose. - Carwoola, Taliesen Road Fire

Once aware that a fire was threatening, people typically began an ongoing process of information search that included communication with others within the threatened area (e.g. relatives, neighbours, NSWRFS members) and information searches via the internet or smart phone apps. Interview data highlight the tendency for people to call or SMS others within the local area to obtain and share information about the fire. These communications often alerted people who were unaware of the fire, in some cases because they were inside working or trying to stay cool.

In some cases, receipt of a warning prompted people to return to their house or property. Of those who were not at home when they found out a bushfire was threatening $(40 \%, \mathrm{n}=99)$, almost three-quarters attempted to return $(71 \%, \mathrm{n}=67) .{ }^{1}$ The main reasons people returned were to defend houses and property, to assist or rescue other household members, and to protect pets and other animals. For example, one interviewee explained how he returned home to protect his livestock after becoming aware of the fire:

We were in town when the fire started... You'll hear a lot of gripes about the police blocking off the road. We stayed there [at the road block] for a little while, but then, because we've got sheep and livestock, we are in habit of using our back neighbour's shearing shed, and so I took my Sedan, car, not built for it, back in through our neighbour's place... I remember a creek crossing, which was very rocky, scraped the car a bit, but we got home. - Carwoola, Taliesen Road Fire

\footnotetext{
${ }^{1}$ This figure is calculated from 95 responses (four respondents did not answer the question).
} 
There were numerous examples where people did not respond to warnings immediately. A key insight from the interview data is that many interviewees received notification of the fire and information relating to its location, direction and rate of spread, then sought visual confirmation in order to make their own assessment of the threat. Direct observation of the fire appears to have helped people ready themselves to begin defending, or confirm the need to leave:

I had the Fires Near You [sic] app ${ }^{2}$, watching it, keeping updated, going up to the top of the hill, driving down to the fire zone, just keeping an idea of where [the fire] is and what's happening. - Cassilis, Sir Ivan Fire

I actually saw the smoke when the fire started. So I smelt the smoke and I drove up to where the fire started. You can see it from Taylors Creek Road. So I drove up [there]... and noticed it was going to be a dangerous fire. - Mount Fairy, Taliesen Road Fire

There were also cases where people received a warning that did not align with their assessment of the risk. For example, one resident threatened by the Sir Ivan Fire could not recall specific information or advice provided in a recorded landline telephone message, but remembered finding it confusing. The degree of danger it conveyed did not align with his assessment that the fire was far away and probably not a threat to him:

It wasn't a personal call, it was a recording. But it was confusing. It didn't say 'You need to evacuate'... I thought, 'Okay, I'm not going to evacuate because it's a long way away and there's a lot of time', and there was no wind. It was hot and shocking, but it wasn't howling or anything. They'd gone off to fight this fire and then I saw, later in the day, planes and I thought: 'Oh f*ck it, it's fine. They've got a really good chance' [of containing the fire]. Anyway... it was confusing. It said something about it being dangerous in the area and I knew all that anyway. So that was that. - Coolah, Sir Ivan Fire

Similarly, a resident in Uarbry explained how the recorded message he received did not align with his assessment of the weather conditions and the seriousness of the bushfire. Direct advice from a police officer eventually motivated him to leave:

\footnotetext{
2 'Fires Near Me' is a NSWRFS mobile phone app that provides warnings and information on incidents across NSW attended by the NSWRFS and other agencies.
} 
The phone would ring and I'd pick it up: 'This is the RFS... You've gotta get out, be prepared. FIRE!', and all the rest of it. But I didn't take heed of that because I'm looking around... Well I just couldn't believe it, that this was an area where it was going to go up like that. I didn't think the fire was as big as it was. But it came on that quick, and I'm glad the police got me out. - Uarbry, Sir Ivan Fire

Responsibilities for animals also delayed or prevented people from responding to warnings. For example, interviewees in Coolah explained how their inability to relocate their horses prevented them from leaving after receiving advice to do so from local police. Similarly, a resident on a small acreage at Carwoola received warning about the fire, which included advice to evacuate, but monitored the progress of the fire using the Fires Near Me app and direct observation to determine whether it was really necessary to leave. She did not want to cause stress for her animals by relocating them unnecessarily, or inconvenience others who might have to help:

I was also keeping an eye on the... Fires Near Me app, the RFS app, for updates as well, just trying to gauge what their response was, whether it was as urgent as what it seemed. Because when you're standing on your block looking at smoke that seemed to be a few kilometres away, it's really hard to get any sense of urgency because it looks like it's going away. And thinking about the logistics of trying to catch squillions of chickens and loading up cars and trailers and inconveniencing people who potentially then might have had to turn around and bring all my birds back again, it was just ... It was really difficult to try and work out whether there was an immediate need to go or not. Then yeah, when the wind changed we realised we just needed to get out.

She explained her dilemma further:

Do you go through that whole evacuation process knowing that the fire looks like it's going away from you and it could be for absolutely nothing? Because animals get very stressed when you grab them in a hurry. The chooks that I did get out all stress-moulted and freaked out, lost all their feathers. Yeah, it was incredibly stressful. - Carwoola, Taliesen Road Fire 
Some people felt the warnings they received caused unnecessary worry or anxiety. An interviewee explained how multiple SMS warnings about the Sir Ivan Fire contributed to his wife's sense of panic. Their plan was to stay and defend their house and farm property, a plan they were already putting into action. He felt the SMS warning was not useful because they were already aware of the fire and preparing to defend. Another interviewee threatened by the Currandooley Fire was upset that her children received SMS warnings on their mobile phones, which they found alarming:

We were already aware of it [the fire]. We knew what was going on and we knew exactly how close it was... What upset me was that the kids were getting [warnings] on their phones. And that's fair enough, because [the warning] just goes out... But you have to think of it from our situation... They go, 'Guys, this is so bad. Our Dad's out there'. So then they worry about dad... - Tarago, Currandooley Fire

In each of the fires there were people who did not receive an official warning or, received a warning after learning about the fire ('too late'). Limited mobile phone coverage impeded delivery of SMS warnings in each of the fires, but was most apparent in areas affected by the Sir Ivan Fire. It is important to note that limited mobile phone coverage is an everyday challenge in many of these areas, so most people were not relying on receiving a SMS warning.

Nevertheless, interviewees saw the benefits that would come with better mobile phone coverage, including a greater capacity to communicate in emergencies.

\section{Discussion}

This research provides a case study of how people understood and responded to warning messages sent during the 2017 New South Wales bushfires. Overall, our results suggest that most people who received warnings about Catastrophic fire danger or actual bushfires in NSW in 2017 found them easy to understand and considered them to be useful. However, this did not mean that all people responded to warnings in ways intended by fire services. While some people promptly took protective action after receiving a warning, the research found that many people waited until they were directly threatened before taking action. This finding is consistent with previous bushfire research (e.g. Rhodes 2005; Tibbits and Whittaker 2007; McLennan et al. 2013 and 2015). 
Also consistent with previous studies, this research highlights that, before taking protective action, people will almost always attempt to confirm bushfire warnings by surveying the environment or communicating with other people (Perry 1979). When they are unable to confirm the threat, usually because it is not certain that they will be affected, warning response is often delayed or avoided. Our research identifies a number of reasons people attempt to confirm bushfire warnings. First, people seem to have some understanding of the dynamic nature of bushfires and the possibility they will not be impacted. In the case of warnings about fire danger conditions, there may not be a fire when the message is received. Even when there is a fire, impact is not certain due to factors such as wind direction and the activities of firefighters. As such, people may attempt to confirm that they are threatened to avoid unnecessary evacuation and its associated costs (e.g. time, effort, distress). The cost-effectiveness of evacuation is a particularly important consideration for those responsible for pets and animals, which may be difficult to move or stressed by relocation (Heath et al. 2001; Thompson et al. 2018; Day 2017), as well as those who are engaged in economic activities such as farming, where unnecessary evacuation may impose unacceptable financial costs (see Whittaker et al. 2012; Smith et al. 2015). Second, while people seem to have some understanding of the dynamic nature of bushfires, they may not understand how fast fires can travel. There were numerous instances in our research where warnings advised people to take protective action, yet they could not confirm the threat because the fire seemed too far away or because some other factor such as observed wind speed suggested it was not a threat. This mismatch between the information contained in a warning and a person's expectations of the fire's behaviour may lead to additional attempts to try to confirm the situation.

Clearly then, and despite most of our survey respondents indicating that they found bushfire warnings easy to understand, many people did not respond to warnings as fire services had hoped. Does this mean that bushfire warnings were not effective? There is relatively little research on the effectiveness of bushfire warnings. While qualities such as 'usefulness', 'timeliness' and 'accuracy' can be assessed by questioning those who receive warnings, it is more difficult to discern whether a warning has prompted 'appropriate' responses. This is because there is no 'one' appropriate response to bushfire. Australians have the option to decide whether they will evacuate or stay to defend their house or property against bushfire, and receipt of a warning may prompt either of these responses (or even a mix of responses within a household). Furthermore, the circumstances of those at risk may necessitate different responses to warning messages. For example, a warning issued during the 2018 Reedy Swamp fire in Bega 
Valley (NSW) advised people in the town of Tathra to shelter as the fire arrived because evacuation was no longer considered a safe option. Those who were north of the Bega River were advised to leave if their path was clear to the north. For the latter, an appropriate response to this warning depended on their assessment of the hazardousness of their evacuation route, which may have been affected by fire, fallen trees or other hazards. For these reasons, 'compliance' is not a meaningful or useful measure of warning effectiveness in the bushfire context. Accordingly, Handmer (2000) argues that warning providers should be held responsible for producing warning messages that are meaningful for intended audiences and not for people's decision-making, which is highly context-dependent.

Indeed, our research draws attention to three key messages in bushfire warnings that are not personally meaningful for many people because they do not align with how they are likely to respond to a bushfire. First, in relation to warnings about Catastrophic fire danger, most people do not intend to leave bushfire risk areas unless there is a fire. Advice to leave before there is a fire is widely seen as impractical and ignored. In this study, just one-in-ten respondents left for a place of safety after receiving a Catastrophic fire danger warning and one-in-ten said they would respond to future warnings in this way. These findings support earlier studies that found only small proportions of people evacuated based on official warnings about fire danger conditions (Strahan Research 2010; McLennan et al. 2013, 2015). In addition to being seen as offering impractical advice, Catastrophic fire danger warnings lack the degree of specificity that is needed to motivate most people to take protective action. As Wood et al. (2018) note, warnings are unlikely to encourage protective action if they fail to provide specific details about the threat, who will be affected, and necessary protective actions. Given that this advice is seen as impractical, and the inherent lack of specificity in warnings, enhanced messaging is unlikely to be effective in increasing the number of people who leave in the absence of fire on Catastrophic fire danger days.

Second, many people do not accept the message that houses are not defendable under Catastrophic conditions. In this study, four-in-ten respondents who received a warning about Catastrophic fire danger began readying equipment to protect their house or property. More than a quarter said they would do the same in response to a future warning. The legacy of the 'stay and defend' approach in Australia should not be underestimated. As Handmer and Tibbits (2005) have documented, the approach evolved from traditions of rural self-reliance and household firefighting practices throughout Australia. Given these longstanding traditions, it is 
understandable that changes to policy and messaging in the relatively short time since Black Saturday are not yet widely accepted or implemented. Studies of bushfires since 2009 have consistently found that a substantial proportion of people continue to stay and defend against bushfire, including under Catastrophic conditions (McLennan et al. 2015; Wilkinson and Eriksen 2015). Findings from this research also support previous studies that highlight the strong resolve of agricultural landholders to stay and defend their homes, livestock and livelihoods against fires (Whittaker et al. 2012; Smith et al. 2015). Enhanced messaging may motivate some people to leave in a timely manner; however, it is unlikely to persuade those who are committed to remaining at their home or property to evacuate.

Third, our findings suggest that many people do not understand or accept the 'leave early' message. Earlier research into public understandings of the 'Prepare, Stay and Defend or Leave Early' (PSDLE) policy identified confusion over what 'leave early' means (i.e. what constitutes 'early') and at what point the decision should be made (Tibbits and Whittaker 2007). McLennan et al.'s (2012, p.923) analysis of interviews with residents affected by the Murrindindi fire on Black Saturday reached a similar conclusion, finding that research participants had a clearer understanding of 'staying and defending' than 'leaving early' due to an overemphasis on property defence in bushfire safety education. However, our findings also suggest that many people reject the 'leave early' message because they want to avoid unnecessary evacuation and its associated costs. This process of confirming warnings and threats has been characterised in warnings research as 'milling' (Wood et al. 2018), implying a degree of inaction and confusion. Yet our results suggest that, at least in the context of bushfire, the process of confirmation can be an active and purposeful one.

What, then, can be done to facilitate more timely responses to warnings? We argue that it is important to acknowledge and work within the context in which warnings are understood, interpreted and acted upon by members of the community. In terms of warning messages, there is scope to improve the content and wording to more clearly communicate the threat posed by bushfires and the need to take protective action. For example, our research found that, even under Catastrophic fire danger conditions, some people underestimated the speed at which fire can move through the landscape. Enhanced education and risk communication in warnings - for instance by describing possible rates of spread and likely impacts of fires in prevailing conditions - may help people to better understand the threat posed by fires. However, our results suggest that confirmation remains an inevitable feature of the warning process. Enhanced 
warning messages may reduce the tendency for some people to seek confirmation (Wood et al. 2018); however, authorities should also consider ways to help people confirm warnings. For example, the NSWRFS now deploys Community Field Liaison Officers (CFLOs) to public places and known observation points to meet people at a time when they are searching for and receptive to information. CFLOs can provide information and advice to help people confirm warning messages and take timely protective action. Consideration should also be given to ways to help people confirm warnings without travelling to observe a fire themselves. For example, fire services' sharing of their own and local people's photos and videos of the fire via social media could help people to personalise and confirm the threat, particularly when local people and landmarks are featured. Furthermore, given the propensity for people threatened by bushfire to leave when they see others doing so (Strahan 2017; McCaffrey et al. 2018), it may be productive to share images of local people leaving the fire threatened area. Initiatives such as these may help people to confirm warning messages, respond in a timely manner and avoid the risks associated with last minute evacuation or entrapment at their home or property.

As discussed above, warnings that are not personally meaningful to people are unlikely to motivate desired protective action, regardless of how they are worded. Advice to leave before there is a fire on Catastrophic fire danger days is widely seen as impractical, and the suggestion to 'leave early' is often ignored because people do not want to evacuate unnecessarily. Similarly, some people reject the assertion that houses are not defendable under Catastrophic conditions and intend to protect not just houses but other valued things such as animals, gardens, buildings, sheds and livelihood assets (e.g. agricultural equipment, vehicles, fences, pasture). Clearly, many people will be at home (or return home) when a fire threatens and, if they intend to evacuate, will not leave until they are reasonably certain they will be impacted. Given the risks associated with last-minute evacuation, fire services are likely to continue to advise people to 'leave early'. Providing greater clarity and specificity about what this means - for example by recommending timeframes for specific areas - may help some people to leave before they are directly threatened. However, greater consideration should also be given to strategies that recognise the reality that many people will be at home when a fire threatens, including on Catastrophic days. Insights from warning research suggest warnings and advice that encourage people to evacuate as soon as a fire is threatening are more likely to be effective if they describe the threat posed, possible consequences, and how people can take action to reduce such consequences (Wood et al. 2018). 


\section{Conclusion}

This paper has examined how people who were threatened and affected by bushfires in NSW, Australia, in 2017 understood, interpreted and acted upon warning messages they received. Our findings highlight the tendency for people to seek confirmation that they are threatened before taking protective action. This is consistent with findings from previous research and provides further evidence for the importance of this behaviour in people's responses to threat from natural hazards. Most commonly, people sought to confirm the threat because they were not certain they would be impacted and wanted to avoid unnecessary evacuation and its associated costs. While there may be scope to improve the content and wording of warnings to better communicate the threat posed by bushfires and the need for protective action, our own and others' research suggests that confirmation is an inevitable feature of the warning process. Further, we suggest in contrast to previous research that, in the context of bushfire, the process of confirmation can be an active and purposeful one. Consequently, rather than concentrating on attempts to reduce confirmation through enhanced messaging, it may be productive for fire and emergency services to give greater consideration to ways they might help people to confirm warning messages. The NSWRFS's use of Community Field Liaison Officers during bushfires is one example.

Critically, it is important for fire agencies to understand that many people do not accept some of the key messages they are providing to the community: (1) that people should leave bushfire risk areas on days of Catastrophic fire danger, before there is a fire; (2) that houses are not defendable under Catastrophic conditions; and (3) that people should 'leave early'. Despite changes in policy and messaging since Black Saturday emphasising 'leaving early' as the safest option, some people remain committed to staying to defend, many remain confused about the meaning of 'leave early' and, upon receiving a warning, most will wait until they can confirm the warning before taking protective action. It is clear that many people will be at home or return home when a fire threatens and, if they intend to leave, are unlikely to do so until they are reasonably certain they will be impacted. While changing such behaviour may be desirable, at the same time it is important to acknowledge and work within the context in which warnings are understood, interpreted and acted upon by members of the community.

\section{Acknowledgements}

This paper is based on research funded by the New South Wales Rural Fire Service (NSWRFS) and undertaken through the Bushfire \& Natural Hazards Cooperative Research Centre 
(BNHCRC). Special thanks are due to: Anthony Clark and Anthony Bradstreet from the NSWRFS; John Bates and Nathan Maddock from the BNHCRC; the many researchers and fire service personnel who assisted with data collection and provided support in the field; and the journal's anonymous reviewers. Most of all, we thank our research participants who generously shared their time and experiences of the bushfires. The views expressed in this paper are those of the authors and do not necessarily reflect the views of the NSWRFS or BNHCRC.

\section{References:}

Anderson-Berry, L., Achilles, T., Panchuk, S., Mackie, B., Canterford, S., Leck, A., Bird, D.K. (2018) Sending a message: how significant events have influenced the warnings landscape in Australia. International Journal of Disaster Risk Reduction 30, pp. 5-17.

Attorney-General's Department (2013) Australia's emergency warning arrangements. Available at:

https://www.ag.gov.au/Publications/Documents/AustraliasEmergencyWarningArrangements/Au stralias-Emergency-Warning-Arrangements.pdf, verified 31 October 2018.

Australasian Fire and Emergency Services Authorities Council (AFAC) (2012) Bushfires and community safety. Available at:

https://www.afac.com.au/insight/doctrine/article/current/bushfires-and-community-safety, verified 31 October 2018.

Australian Emergency Management Committee (2009) Australia's revised arrangements for bushfire advice and alerts. Available at: https://knowledge.aidr.org.au/media/6003/ausarrangements-bushfire-advice-alerts.pdf, verified 12 September 2019.

Bassett, T.J., Fogelman, C. (2013) Déjà vu or something new? The adaptation concept in the climate change literature. Geoforum 48, pp. 42-53.

Bean, H., Sutton, J., Liu, B.F., Madden, S., Wood, M.M., Mileti, D.S. (2015) The study of mobile public warning messages: a research review and agenda. Review of Communication 15 (1), pp. 60-80. 
Blanchi, R., Leonard, J., Haynes, K., Opie, K., James, M., Dimer de Oliveira, F. (2014)

Environmental circumstances surrounding bushfire fatalities in Australia 1901-2011.

Environmental Science \& Policy 37, pp. 192-203.

Brenitz, S. (1983). Cry Wolf: The psychology of false alarms. Hilsdale, NJ: Lawrence Erlbaum.

Bradfield, A., Wells, G.L. (2005) Not the same old hindsight bias: outcome information distorts a broad range of retrospective judgements. Memory and Cognition 33, pp. 120-30.

Brotzge, J., Donner, W. (2013) The tornado warning process: a review of current research, challenges, and opportunities. Bulletin of the American Meteorological Society, November 2013, pp. 1715-33.

Cheshire, L. (2015) 'Know your neighbours': disaster resilience and the normative practices of neighbouring in an urban context. Environment and Planning A 47, pp. 1081-99.

Cohn, P.J., Carroll, M.S., Kumagai, Y. (2006) Evacuation behavior during wildfires: results of three case studies. Western Journal of Applied Forestry 21 (1), pp. 39-48.

Couling, M. (2014) Tsunami risk perception and preparedness on the east coast of New Zealand during the 2009 Samoan Tsunami warning. Natural Hazards 71 (1), pp. 973-86.

CSIRO (2018) McArthur Mk5 Forest Fire Danger Meter. Available at: https://www.csiro.au/en/Research/Environment/Extreme-Events/Bushfire/Fire-dangermeters/Mk5-forest-fire-danger-meter [verified 12 April 2019].

Day, A.M. (2017) Companion animals and natural disasters: a systematic review of literature. International Journal of Disaster Risk Reduction 24, pp. 81-90.

DeCelles, J.L. (1991) The delayed GPWS response syndrome. Herndon, VA: Aviation Research and Education Foundation. 
Dow, K., Cutter, S.L. (1998) Crying wolf: repeat responses to evacuation orders. Coastal Management 26 (4), pp. 237-252.

Drabek, T.E. (1999) Understanding disaster warning responses. The Social Science Journal 36 (3), pp. 515-23.

Emergency Management Australia (1998) Australian Emergency Management Glossary. Available at: https://knowledge.aidr.org.au/media/1974/manual-3-australian-emergencyglossary.pdf, verified 31 October 2018.

Every, D., Reynolds, A., Clarkson, L., Bearman, C., Matthews, R., Haigh, L., Dawson, D. (2016) Capturing community experiences in the 2015 Samson Flat fire. Report for the South Australia Country Fire Service. Bushfire \& Natural Hazards CRC, East Melbourne.

Handmer, J. (2000) Are flood warnings futile? Risk communication in emergencies. The Australasian Journal of Disaster and Trauma Studies 2000-2.

Haynes, K., Handmer, J., McAneney, J., Tibbits, A., Coates, L. (2010) Australian bushfire fatalities 1900-2008: exploring trends in relation to the 'Prepare, stay and defend or leave early' policy. Environmental Science and Policy 13, pp. 185-194.

Heath, S.E., Kass, P.H., Beck, A.M., Glickman, L.T. Human and pet-related risk factors for household evacuation failure during a natural disaster. American Journal of Epidemiology 153 (7), pp. 659-665.

Horsey, B., Penman, T. (2014) Community understanding and awareness of bushfire safety: October 2013 bushfires. Report for the Bushfire Cooperative Research Centre and NSW Rural Fire Service. University of Wollongong, Wollongong.

Lavrakas, P.J. (2008) Encyclopedia of survey research methods. Sage Publications, Thousand Oaks.

Lindell, M. and Perry, R. (1992) Behavioral foundations of community emergency planning. Hemisphere Publishing Co., Washington. 
Mackie, B. (2014) Warning fatigue: insights from the Australian bushfire context thesis. Doctoral thesis, University of Cantebury.

Marshall, C., Rossman, G.B. (2014) Designing qualitative research. Sixth edition. Sage Publications, Thousand Oaks.

McCaffrey, S., Rhodes, A., Stidham, M. (2015). Wildfire evacuation and its alternatives: perspectives from four United States' communities. International Journal of Wildland Fire 24 (2). pp. 170-78.

McCaffrey, S., Wilson, R., Konar, A. (2018) Should I stay or should I go now? Or should I wait and see? Influences on wildfire evacuation decisions. Risk Analysis 38 (7), pp. 1391-1404.

McGee, T. K. (2019). Preparedness and Experiences of Evacuees from the 2016 Fort McMurray Horse River Wildfire. Fire 2 (1), pp. 13.

McLennan, J., Elliott, G., Omodei, M., Whittaker, J. (2013) Householders'safety-related decisions, plans, actions and outcomes during the 7 February 2009 Victorian (Australia) wildfires. Fire Safety Journal 61, pp. 175-84.

McLennan, J., Every, D., Bearman, C., Wright, L. (2017) On the concept of denial in natural hazard risk and its use in relation to householder wildfire safety in Australia. International Journal of Disaster Risk Reduction 21, pp. 176-86.

McLennan, J., Paton, D., Wright, L. (2015) At-risk householders' responses to potential and actual bushfire threat: an analysis of findings from seven Australian post-bushfire interview studies 2009-2014. International Journal of Disaster Risk Reduction 12, pp. 319-27.

McLennan, J., Ryan, B., Bearman, C., Toh, K. (2019) Should we leave now? Behavioral factors in evacuation under wildfire threat. Fire Technology 55 (2), pp. 487-516.

Mileti, D. (1999) Disasters by design: a reassessment of natural hazards in the United States. Joseph Henry Press, Washington D.C. 
Mileti, D. (2004) Public hazards communication and education: the state of the art. Institute of Behavioural Science, University of Colorado: Boulder, CO.

Mileti, D., Sorensen, J. (1990) Communication of emergency public warnings: a social science perspective and state-of-the-art assessment. Oak Ridge National Laboratory, Tennessee.

Nagarajan, M., Shaw, D., Albores, P. (2012) Disseminating a warning message to evacuate: a simulation study of the behaviour of neigbours. European Journal of Operations Research 220 (3), pp. 810-19.

New South Wales Rural Fire Service (2018) Fire Danger Ratings. Available at: https://www.rfs.nsw.gov.au/fire-information/fdr-and-tobans?a=1421, verified 31 October 2018.

Omori, H., Kuligowski, E.d., Gwynne, S.M.V., Butler, K.M (2017) Human response to emergency communication: a review of guidance on alerts and warning messages for emergencies in buildings. Fire Technology 53 (4), pp. 1641-68.

Parker, D.J., Handmer, J.W. (1998) The role of unofficial flood warnings. Journal of Contingencies and Crisis Management 6 (1), pp. 45-60.

Parker, D. J., Priest, S.J., Tapsell, S.M. (2009). Understanding and enhancing the public's behavioural response to flood warning information. Meteorological Applications 16 (1)\, pp. 103-114.

Paveglio, T. B., Boyd, A.D., Carroll, M.S. (2012). Wildfire evacuation and its alternatives in a post-Black Saturday landscape: catchy slogans and cautionary tales. Environmental Hazards 11(1), pp. 52-70.

Penman T, Eriksen C, Blanchi R, Chladil M, Gill AM, Haynes K, Leonard J, McLennan J, Bradstock RA (2013) Defining adequate means of residents to prepare property for protection from wildfire. International Journal of Disaster Risk Reduction 6, pp. 67-77. 
Perry, R. W. (1979). Evacuation decision-making in natural disasters. Mass Emergencies 4, pp. 25-38.

Rhodes, A. (2005) Stay or go: what do people think of the choice? Available at: http://www.bushfirecrc.com/sites/default/files/managed/resource/stay_or_go_-_ar.pdf, verified 29 November 2018.

Sharma, U., Patt, A. (2012) Disaster warning response: the effects of different types of experience. Natural Hazards 60, pp. 409-23.

Sorensen, J.H. (2000) Hazard warning systems: review of 20 years of progress. Natural Hazards Review 1 (2), 119-25.

Strahan, K. (2018) Factors influencing householder self-evacuation in two Australian bushfires. $\mathrm{PhD}$ thesis. RMIT University, Melbourne.

Strahan, K., Whittaker, J. and Handmer, J. (2013) Self-evacuation archetypes in Australian bushfire. International Journal of Disaster Risk Reduction 27, 307-316.

Strahan Research (2010) Behaviour and intentions of households on Code Red days. A report for the Country Fire Authority. Strahan Research, Melbourne.

Stevenson, A. (Ed.) (2010) Oxford Dictionary of English. Oxford University Press, Oxford.

Teague, B., McLeod, R., and Pascoe, S. (2009) 2009 Victorian Bushfires Royal Commission: interim report. State Government of Victoria, Melbourne.

Teague B., McLeod R., Pascoe S. (2010) 2009 Victorian Bushfires Royal Commission final report: summary. Available at:

http://www.royalcommission.vic.gov.au/finaldocuments/summary/HR/VBRC_Summary_HR.pd f [Verified 15 January 2019]

Thomas, D.R. (2006) A general inductive approach for analysing qualitative evaluation data. American Journal of Evaluation 27 (2), pp.237-46. 
Thompson, K.R., Haigh, L., Smith, B.P. (2018) Planned and ultimate actions of horse owners facing a bushfire threat: implications for natural disaster preparedness and survivability. International Journal of Disaster Risk Reduction 27, pp. 490-498.

Trigg, J.L., Rainbird, S.,Thompson, K., Bearman, C., Wright, L., McLennan, J. (2015) Capturing community experiences. South Australian bushfires January 2014. Bushfire \& Natural Hazards CRC, East Melbourne.

Walker, R. A. (1979). Review of The environment as hazard. Geographical review 69, pp. $113-$ 114.

Whittaker, J., Handmer, J., Mercer, D. (2012) Vulnerability to bushfires in rural Australia: a case study from East Gippsland, Victoria. Journal of Rural Studies 28, 161-73.

Whittaker J., McLennan J., Elliot, G., Gilbert, J., Handmer, J., Haynes, K., Cowlishaw, S. (2009) Victorian 2009 Bushfire Research Response: final report. Available at: http://www.bushfirecrc.com/sites/default/files/managed/resource/bushfire-crc-victorian-firesresearch-taskforce-final-report.pdf, verified 8 November 2018.

Whittaker, J., Haynes, K., Handmer, J., McLennan, J. (2013) Community safety during the 2009 Australian 'Black Saturday' bushfires: an analysis of household preparedness and response. International Journal of Wildland Fire 22, pp. 841-849.

Whittaker, J., Eriksen, C., Haynes, K. (2016) Gendered responses to the 2009 Black Saturday bushfires in Victoria, Australia. Geographical Research 54 (2), pp. 203-15.

Whittaker, J., Blanchi, R., Haynes, K., Leonard, J., Opie, K. (2017). Experiences of sheltering during the Black Saturday bushfires: Implications for policy and research. International Journal of Disaster Risk Reduction 23, pp. 119-127.

Whittaker, J., Taylor, M. (2018) Community preparedness and responses to the 2017 NSW bushfires: research for the New South Wales Rural Fire Service. Bushfire \& Natural Hazards Cooperative Research Centre and University of Wollongong, Wollongong. 
Wilkinson, C., Eriksen, C. (2015). Fire, water and everyday life: Bushfire and household defence in a changing climate. Fire Safety Journal 78, pp. 102-110.

Wilkinson, C., Eriksen, C., Penman, T. (2016) Into the firing line: civilian ingress during the 2013 'Red October' bushfires, Australia. Natural Hazards 80 (1), pp. 521-38.

Wood, M. M., Mileti, D.S., Bean, H., Liu, B.F., Sutton, J., Madden, S. (2018) Milling and Public Warnings. Environment and Behavior 50 (5), pp. 535-566. 